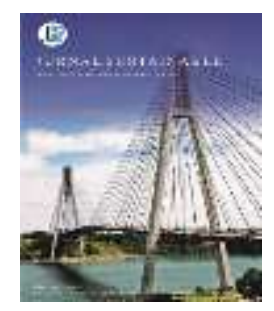

\title{
Implementasi HSV dan GLCM untuk Deteksi Kesegaran Ikan Bawal menggunakan Radial Basis Function Berbasis Android
}

\author{
Muhammad Sarimin ${ }^{1}$, Martaleli Bettiza ${ }^{2}$, Nurul Hayaty ${ }^{3}$, Sapta Nugraha ${ }^{4}$ \\ ${ }^{1,2,3}$ Program Studi Teknik Informatika, Fakultas Teknik, Universitas Maritim Raja Ali Haji \\ ${ }^{4}$ Program Studi Teknik Elektro, Fakultas Teknik, Universitas Maritim Raja Ali Haji \\ 1,2,3,4 Jl. Politeknik Senggarang, Tanjungpinang 29100 \\ *Corresponding Author: saptanugraha@umrah.ac.id
}

\begin{abstract}
Tanjungpinang is one of the fish producing cities. fish with a good level of freshness are needed to produce quality fish products. In this case, a system is needed that can recognize fresh and non-fresh fish. In this study using the HSV and GLCM methods as a feature then image recognition is carried out using the Radial Basis Function (RBF). In the RBF recognition method it is necessary to have a central point that becomes the data center. Data center retrieval uses the KMeans method, where this method greatly determines the success of the RBF's introduction. By determining the best number of data centers in the best data center, it is at number 7 with MAD of 0.98. At the time of image acquisition did not pay attention to lighting so as to produce training data with low quality. How in the introduction process using this RBF gets a low level of accuracy, which is equal to $50 \%$.
\end{abstract}

Keywords-HSV, GLCM, K-Means, RBF.

Intisari- Tanjungpinang menjadi salah satu kota pengolah ikan seperti yang ditemukan di sekeliling kota tanjungpinang. Untuk hasil olahan ikan yang baik membutuhkan bahan dari ikan yang baik, atau ikan yang terjaga tingkat kesegarannya. Dalam hal ini diperlukan sistem yang bisa mengenali ikan yang segar dan yang tidak segar. Pada penelitian ini menggunakan metode HSV dan GLCM sebagai ciri dari suatu citra ikan kemudian dilakukan pengenalan dengan salah satu JST yaitu Radial Basis Function (RBF). Dalam metode pengenalan RBF perlu adanya center yang menjadi pusat data. Pengambilan data center ini menggunakan metode K-Means di mana metode ini sangat menentukan keberhasilan dari pengenalan yang dilakukan RBF. Dengan menentukan jumlah data center terbaik di dapat niali terbaik sebagai pusat data yaitu pada angka 7 dengan MAD sebesar 0,98 . Pada pengambilan citra yang tidak memperhatikan pencahayaan nya menghasilkan data latih yang tidak bagus untuk data latih. Sehingga pada proses pengenalan mengunakan RBF ini mendapatkan tingkat akurasi yang rendah, yaitu sebesar $50 \%$.

Kata kunci-HSV, GLCM, K-Means, RBF.

\section{Pendahuluan}

Tanjungpinang merupakan ibukota Kepulauan Riau, Indonesia. Adapun luas wilayah Tanjungpinang adalah sebesar 258.82 KM2 (BPS Kota Tanjungpinang, 2018).
Sebagaimana yang kita ketahui, Tanjungpinang dikelilingi oleh hamparan pulau yang tidak lepas kaitanya dengan laut dan tentunya olahan hasil laut. Tanjungpinang menjadi salah satu kota pengolah hasil ikan seperti yang banyak 
ditemukan di sekitaran kota Tanjungpinang. Untuk menghasilkan produk olahan ikan yang terbaik, tentunya juga dibutuhkan ikan yang baik untuk di konsumsi, yaitu ikan yang masih terjaga tingkat kesegarannya. Salah satu ciri yang menandakan bahwa ikan tersebut tergolong dalam tingkat kesegaran yang tinggi atau rendah adalah dengan memperhatikan warna mata dan tekstur yang jernih. Kedua hal tersebut merupakan bagian penting dalam mengukur tingkat kesegaran ikan.

Dalam pengolahan citra terdapat beberapa metode yang dapat mengenali warna, salah satunya HSV yang merupakan turunan dari model warna RGB. HSV merupakan singkatan dari Hue, Saturation, dan Value. Hue merepresentasikan warna yang sebenarnya, Saturation menyatakan tingkat kemurnian warna dan Value yang dinyatakan sebagai perubahan warna putih menuju abu-abu yang terakhir mencapai ke warna hitam atau yang di kenal sebagai aras keabuan atau grayscale.

Sedangkan penanganan tekstur, terdapat beberapa metode salah satunya adalah GLCM. GLCM merupakan singkatan dari Gray Level Matrix Co-Occurance adalah suatu metode statistik yang dapat digunakan untuk analisis tekstur. Matrix co-occurance dibentuk dari suatu citra dengan melihat pixel-pixel yang berpasangan yang memiliki intensitas tertentu sehingga dengan menggunakan GLCM, tekstur dengan tingkat kesegaran yang tinggi ataupun rendah dapat dikenali.

Selain ekstraksi warna dan tekstur, digunakan pengenalan dengan salah satunya Jaringan Syaraf Tiruan (JST) yaitu metode Radial Basis Function (RBF) dimana [1] RBF memberikan hasil yang rinci mengenai informasi informasi pada sebuah citra. Untuk menggunakan metode RBF perlu adanya data center agar mendapatkn hasil yang lebih baik.

Penentuan ini di lakukan dengan menggunakan metode K-Means agar memberikan nilai data center yang terbaik bagi data latih. Akhir dari penelitian ini akan menghasilkan sebuah aplikasi berbasis android yang bisa mendeteksi kesegaran ikan.

\section{LANDASAN TEORI}

\section{A. Model Warna Hue Saturation Value $(H S V)$}

Pada dasarnya, warna warna yang kita lihat merupakan spektrum cahaya yang di pantulkan oleh benda, kemudian di tangkap oleh indra penglihatan manusia (mata), lalu di kenali sebagai warna tertentu oleh otak manusia [2].

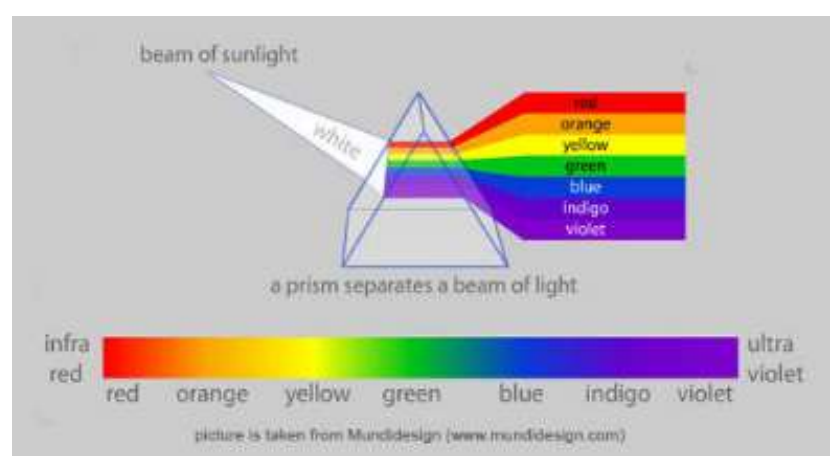

Gambar 1. Spektrum warna

HSV merupakan singkatan dari Hue, Saturation dan Value. Hue merepresentasikan warna yang sebenarnya, seperti merah, hijau, biru dan lain lainnya yang di tangkap oleh indra penglihatan manusia berdasarkan Panjang gelombang yang di hasilkan. Nilai dari Hue merupakan sudut putar yang bernilai $0^{\circ} \mathrm{s} / \mathrm{d}$ $360^{\circ}$.

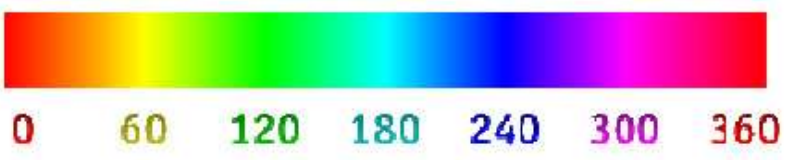

Gambar 2. Skema sudut warna Hue

Saturation menyatakan tingkat kemurnian suatu warna atau banyaknya cahaya putih yang tercampur dengan Hue. Nilai dari Saturation dan intensitas bernilai $0 \mathrm{~s} / \mathrm{d} 1$ dinyatakan sebagai ratio dimana 0 berarti gray dan 1 berarti murni.

Value merupakan atribut yang menyatakan banyaknya cahaya yang diterima oleh mata tanpa memerdulikan warna, dinyatakan sebagai perubahan warna putih menuju abu-abu dan terakhir mencapai ke warna hitam atau yang dikenal sebagai aras keabuan atau grayscale. Nilai dari Value dinyatakan dengan 0 s/d 1, 0 untuk hitam dan 1 untuk putih. Konversi RGB ke HSV menggunakan persamaan (1), (2), (3), dan (4). 


$$
\begin{aligned}
& V=\max (r, g, b) \\
& S= \begin{cases}0 & \text { Jika } V=0 \\
V-\frac{\min (r, g, b)}{V} & \text { jika }=\left\{\begin{array}{l}
V=0 \\
V>0
\end{array}\right.\end{cases} \\
& H= \begin{cases}0 & \frac{60(g-b)}{S V} \\
60\left[2+\frac{(b-r)}{S V}\right] & \text { jika }=\left\{\begin{array}{l}
S=0 \\
V=r \\
V=g \\
60\left[4+\frac{(r-g)}{S V}\right]
\end{array}\right. \\
\mathrm{H}=\mathrm{H}+360 & \text { Jika } H<0\end{cases}
\end{aligned}
$$

\section{B. Gray Level Co-occurance Matrix (GLCM)}

Menurut Kadir dan Susanto (2012) dalam [3] mengatakan bahwa Matrix Co-Occurance (matriks kookurensi) awalnya merupakan usulan dari Haralick pada tahun 1973. Merupakan suatu metode statistik yang dapat digunakan untuk analisis tekstur. Tekstur adalah sifat-sifat atau karakteristik yang dimiliki oleh suatu daerah di dalam citra yang cukup besar sehingga secara alami sifat-sifat atau karakteristik tersebut dapat berulang dalam daerah tersebut, dengan kata lain tekstur dapat diartikan dengan keteraturan polapola tertentu dimana susunan pixel-pixel dalam citra yang membentuk pola pola tersebut [4].

\section{Berikut tahapan untuk menyelesaikan GLCM:}

\section{Citra Grayscale}

Citra grayscale merupakan citra digital yang hanya memiliki satu nilai pada setiap pikselnya. Setiap piksel dari citra grayscale diwakili oleh satu byte, dengan kata lain nilai bagian $R e d=$ Green $=$ Blue. Nilai tersebut digunakan untuk menunjukkan tingkat intensitasnya. Warna yang dimiliki adalah warna dari hitam, keabu-abuan hingga putih.

Konversi RGB ke Grayscale bertujuan agar menyerhanakan proses perhitungan objek pada sebuah citra. Konversi tersebut memerlukan nilai R-layer, G-layer, dan B-layer pada sebuah citra dan menjadi matriks yang akan digunakan untuk konversi RGB ke grayscale dimana hal tersebut dapat dilakukan dengan menggunakan persamaan (5):

$$
\text { Grayscale }=\frac{R+G+B}{3}
$$

\section{Matriks Kookurensi}

Matriks kookurensi dibentuk dari suatu citra dengan melihat pixel-pixel yang berpasangan yang memiliki intensitas tertentu. Penggunaan metode ini berdasar pada hipotesis bahwa dalam suatu tekstur akan terjadi perulangan konfigurasi atau pasangan aras keabuan. Dalam matriks kookurensi terdapat beberapa ciri tekstur yang dapat diperoleh dari citra yang akan digunakan sebagai pembeda antara citra satu dengan yang lainya [4].

Berikut langkah-langkah mendapatkan fitur GLCM :

a. Konversi matrik intensitas ke matrik kookurensi

Langkah ini dilakukan dengan menghitung pasangan piksel yang memiliki intensitas yang sama dan dengan orientasi sudut tertentu, serta memasukkan nilai pasangan piksel ke dalam area matrik GLCM, sehingga menghasilkan matrik kookurensi.

b. Merubah matrik kookurensi ke matrik simetris

Langkah selanjutnya yaitu menambahkan matriks kookurensi yang telah terbentuk dengan matriks transposenya sehingga dihasilkan matriks simestris.

\section{c. Normalisasi matrik GLCM}

Langkah selanjutnya matriks yang telah simetris harus di normalisasikan, elemenelemennya dinyatakan dengan probabilitas.

d. Mencari nilai rata-rata matrik GLCM keempat sudut

Langkah selanjutnya setelah memperoleh matriks kookurensi dari masing-masing sudut maka akan dicari matriks kookurensi rata-rata.

Untuk mendapatkan fitur GLCM, hanya besaran yang diusulkan Harlick yang digunakan. Sebagai contoh (Newsam dan Kammath, 2005) dalam [5] hanya menggunakan lima besaran untuk GLCM, di antaranya sebagai berikut:

1. ASM (Angular Second Moment)

2. Kontras (Contrast)

3. IDM (Inverse Difference Momentum)

4. Entropi (Entropy)

5. Korelasi (Correlation) 
M. Sarimin, N. Hayaty, M. Bettiza, dan S. Nugraha, Implementasi HSV dan GLCM untuk Deteksi Kesegaran Ikan Bawal Menggunakan Radial Basis Function Berbasis Android

\section{C. $\quad$ Algoritma K-means}

Menurut [6] Algoritma K-means merupakan suatu metode penganalisaan data atau metode data mining yang melakukan proses pemodelan tanpa supervisi (unsupervised) dan merupakan salah satu metode yang melakukan pengelompokan data dengan sistem partisi.

Metode K-Means
mengelompokkan data yang ada kedalam
beberapa kelompok, dimana data dalam satu
kelompok mempunyai karakteristik yang sama
satu sama lainnya dan mempunyai karakteristik
yang berbeda dengan data yang ada didalam
kelompok yang lain. Algoritma dasar pada K-
Means dapat di lihat sebagai berikut:

1. Normalisasi data dengan menggunakan persamaan (6):

$$
\text { Normalisasi }=\frac{x-\min }{\max -\min }
$$

2. Tentukan jumlah kluster (k), tetapkan pusat kluster sembarang

3. Hitung jarak setiap data ke pusat kluster menggunakan persamaan (7):

$$
d_{i k}=\sqrt{\sum_{j=1}^{m}\left(c_{i j}-c_{k j}\right)^{2}}
$$

4. Kelompokkan data ke dalam kluster yang dengan jarak yang paling pendek

5. Hitung pusat kluster yang baru menggunakan

\section{Radial Basis Function (RBF)}

Jaringan Radial Basis Function (RBF) merupakan pemetaan fungsi tak linier multidimensional yang tergantung kepada jarak antara vektor input dan vektor center. Radial Basis Function (RBF) memiliki topologi jaringan yang terdiri atas unit lapisan masukan (input), unit lapisan tersembunyi (hidden), dan unit lapisan keluaran (output).

Tahapan dalam Radial Basis Function (RBF) memiliki dua tahapan. Yaitu tahap clustering data dan pembaharuan bobot. Pada tahapan pertama data di-clustering atau di kelompokkan berdasarkan kedekatan tertentu. Penentuan cluster dengan sendirinya akan menghasilkan pusat (center) dari kelompok data. Jumlah cluster nantinya akan menjadi penentu hidden unit yang dipakai. Penentuan cluster terdapat dua cara, yaitu pertama dengan cara penentuan pusat secara acak dari kelompok data. Cara ini terbilang cara yang mudah.

Penentuan cluster dengan cara kedua yaitu dengan menggunakan metode K-means. Cara kedua merupakan cara yang sulit namun lebih baik dibanding dengan penentuan secara acak. Dengan mengunakan metode ini cluster di tentukan dengan sendirinya dan menghasilkan pusat-pusat terbaik bagi data.

Berikut tahapan menggunakan algoritma pelatihan jaringan RBF :

1. Menentukan nilai pusat center menggunakan metode K-means

2. Mencari nilai spread dengan menggunakan persamaan (8):

$$
\text { Nilai spread } \sigma=\frac{J_{\max }}{\sqrt{k_{1}}}
$$

3. Menentukan pusat dalam fungsi gaussian dengan menggunakan persamaan (9):

$$
\varphi(r)=\exp \left(-\frac{r}{2 \sigma^{2}}\right)
$$

4. Membentuk matriks gaussian

5. Menghitung nilai bobot dengan menggunakan persamaan (10):

$$
W=G^{+} d=\left(G^{T} G\right)^{-1} G^{T} d
$$

6. Menghitung output dari RBF dengan menggunakan persamaan (11):

$$
Y_{1}=W_{1} * \varphi_{1}+W_{2} * \varphi_{2}+B
$$

\section{E. Perancangan Sistem}

Alur dari kerja sistem dari keseluruhan metode yang menggunakan HSV, GLCM, $K$ Means, dan RBF untuk deteksi kesegaran ikan ditunjukkan pada Gambar 5. Citra awal yang akan dikenali dapat dilihat pada Gambar 4:
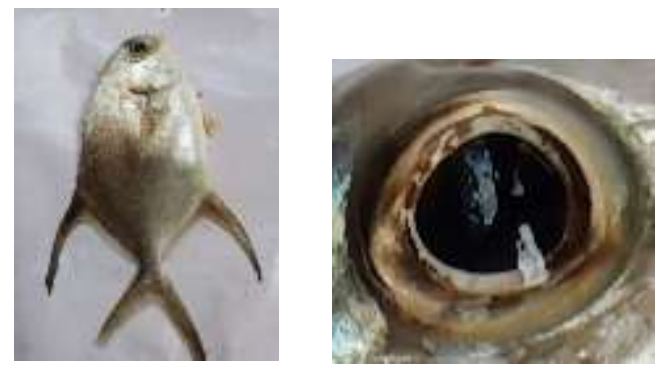

Gambar 4. (kiri) citra ikan utuh (kanan) citra mata ikan 


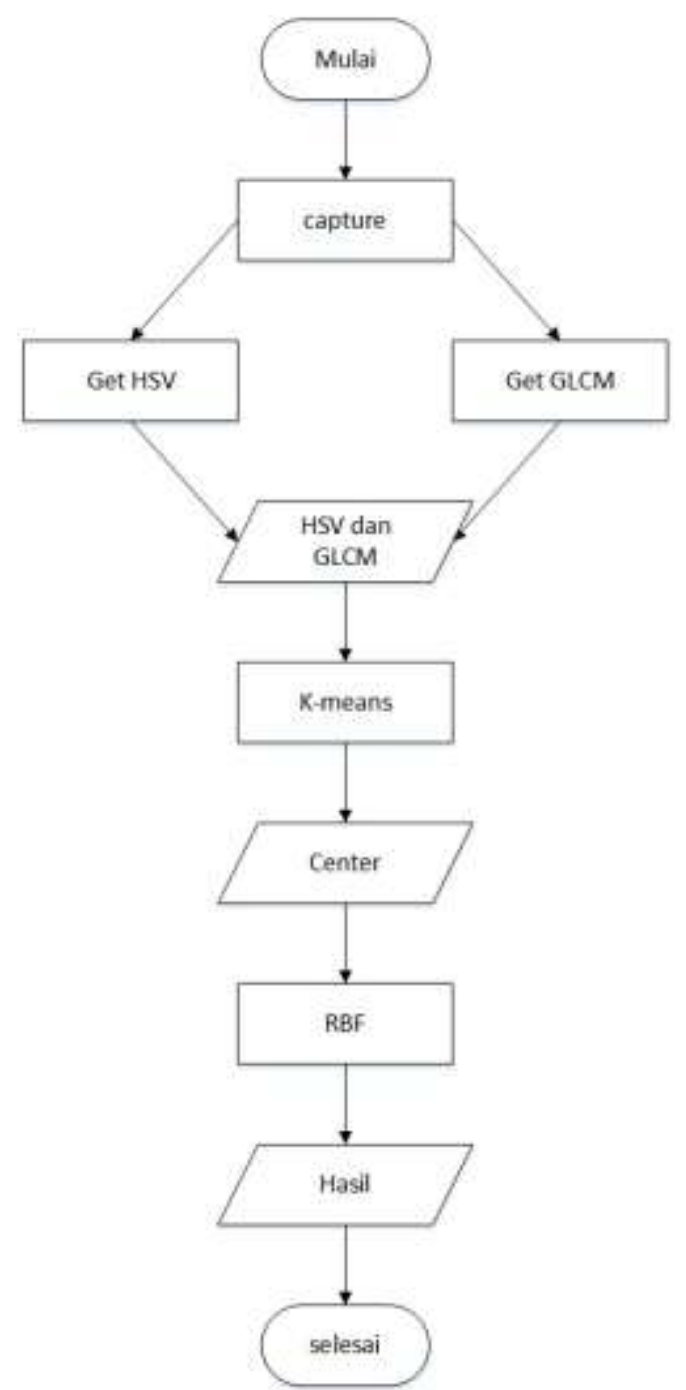

Gambar 5. Flowchart gambaran umum sistem

Pada gambaran umum sistem, sistem memulai dengan akuisisi citra yang kemudian akan di proses dengan mengambil ciri dari citra tersebut. Setelah didapatkan ciri, maka selanjutnya ciri tersebut akan digunakan sebagai inputan untuk mengenali objek hingga didapatkan hasil deteksi kesegarannya.

\section{F. $\quad$ Validasi Data}

Validasi data ini bertujuan untuk melihat tingkat keberhasilan suatu sistem dalam menghasilkan suatu hasil yang sesuai dengan data aktual yang ada. Dalam penelitian ini digunakan Mean Absolute Deviation (MAD) untuk membandingkan data aktual dengan hasil yang di peroleh dari sistem. Berikut persamaan (12) MAD yang akan digunakan:

$$
M A D=\frac{\sum_{t=1}^{n} \mid d_{t}-F_{t}}{n}
$$

\section{Pengujian dan ANalisis}

\section{A. Pengumpulan Data}

Data di ambil dari penakaran ikan berlokasi di Desa Penghujan Kepulauan Riau. Data Ikan sebanyak 5 ekor akan diambil citranya dengan durasi setiap dua jam sekali selama 24 jam. Sehingga satu ikan akan memiliki 12 citra dengan total data sebanyak 60 data. Hal ini dilakukan untuk melihat bagaimana perubahan tingkat kesegaran ikan.

\section{B. Pengujian Centroid}

Centroid atau data center sangat berpengaruh kepada hasil penelitian, dimana data center merupakan data yang digunakan untuk pengenalan sebuah citra. Pada penelitian ini metode untuk mendapatkan data center menggunakan K-Means. Dalam pemilihan center terbaik dilakukan pengujian jumlah center. Jumlah center yang di uji bernilai 3 sampai dengan 30 jumlah center. Hasil dari pengujian data center dapat dilihat pada Tabel 1 .

Tabel 1. Pengujian data center

\begin{tabular}{ccc}
\hline No & Jumlah Kluster & MAD \\
\hline $\mathbf{1}$ & 3 & 1.42332 \\
$\mathbf{2}$ & 4 & 1.08302 \\
$\mathbf{3}$ & 5 & 1.06475 \\
$\mathbf{4}$ & 6 & 1.04694 \\
$\mathbf{5}$ & $\mathbf{7}$ & $\mathbf{0 . 9 8 7 2 2}$ \\
$\mathbf{6}$ & 8 & 1.01572 \\
$\mathbf{7}$ & 9 & 1.04411 \\
$\mathbf{8}$ & 10 & 1.06083 \\
$\mathbf{9}$ & 11 & 1.18859 \\
$\mathbf{1 0}$ & 12 & 1.42325 \\
$\mathbf{1 1}$ & 13 & 1.80285 \\
$\mathbf{1 2}$ & 14 & 1.94762 \\
$\mathbf{1 3}$ & 15 & 1.78345 \\
$\mathbf{1 4}$ & 16 & 1.56317 \\
$\mathbf{1 5}$ & 17 & 1.67882 \\
$\mathbf{1 6}$ & 18 & 1.78602 \\
$\mathbf{1 7}$ & 19 & 1.87766 \\
$\mathbf{1 8}$ & 20 & 1.92161 \\
$\mathbf{1 9}$ & 21 & 1.69549 \\
$\mathbf{2 0}$ & 22 & 1.77218 \\
$\mathbf{2 1}$ & 23 & 2.16486 \\
$\mathbf{2 2}$ & 24 & 2.45144 \\
$\mathbf{2 3}$ & 25 & 2.08184 \\
$\mathbf{2 4}$ & 26 & 1.79141 \\
$\mathbf{2 5}$ & 27 & 1.82558 \\
$\mathbf{2 6}$ & 28 & 1.72672 \\
$\mathbf{2 7}$ & 29 & 2.42565 \\
$\mathbf{2 8}$ & 30 & 1.76622 \\
\hline & & \\
\hline
\end{tabular}




\section{Pengujian Akurasi dan Analisa}

Berdasarkan pengujian data center didapat jumlah center terbaik dengan angka 7. Data center terbaik tersebut akan di gunakan untuk melakukan pengujian tingkat akurasi Aplikasi Pendeteksi Ikan Segar. Hasil dari pengujian tingkat akurasi menggunakan centroid terbaik dapat dilihat pada Tabel 2 .

Tabel 2. Hasil pengujian tingkat akurasi

\begin{tabular}{|c|c|c|c|c|}
\hline No & Data & Target & Hasil & Keterangan \\
\hline 1 & Citra 1 & Segar & Segar & Benar \\
\hline 2 & Citra 2 & Segar & Segar & Benar \\
\hline 3 & Citra 3 & Segar & Sedang & Salah \\
\hline 4 & Citra 4 & Segar & Sedang & Salah \\
\hline 5 & Citra 5 & Sedang & Sedang & Benar \\
\hline 6 & Citra 6 & Sedang & Sedang & Benar \\
\hline 7 & Citra 7 & Sedang & Sedang & Benar \\
\hline 8 & Citra 8 & Sedang & Sedang & Benar \\
\hline 9 & Citra 9 & $\begin{array}{l}\text { Tidak } \\
\text { Segar }\end{array}$ & Sedang & Salah \\
\hline 10 & $\begin{array}{l}\text { Citra } \\
10\end{array}$ & $\begin{array}{l}\text { Tidak } \\
\text { Segar }\end{array}$ & Sedang & Salah \\
\hline 11 & $\begin{array}{l}\text { Citra } \\
11\end{array}$ & $\begin{array}{l}\text { Tidak } \\
\text { Segar }\end{array}$ & Sedang & Salah \\
\hline 12 & $\begin{array}{l}\text { Citra } \\
12 \\
\end{array}$ & $\begin{array}{l}\text { Tidak } \\
\text { Segar }\end{array}$ & Sedang & Salah \\
\hline
\end{tabular}

Dari pengujian pada Tabel 2 dapat dilihat bahwa dari 12 data yang di uji hanya terdapat 6 data yang memiliki keterangan benar, sedangkan 6 data lainnya memiliki keterangan salah sehingga menghasilkan akurasi sebesar $50 \%$.

Rendahnya akurasi disebabkan oleh akuisisi citra yang tidak memperhatikan pencahayaannya. Data ciri yang dihasilkan dari citra tersebut menjadi data yang buruk bagi pelatihan, karena data yang dihasilkan merupakan data yang tidak memiliki rentang yang jauh antara citra ikan segar dan citra ikan tidak segar. Hal ini berpengaruh pada hasil pengenalan yang hanya mengacu pada rata-rata dari nilai target.

\section{UCAPAN TERIMA KASIH}

Terimakasih yang tidak terhingga kami ucapkan kepada Universitas Maritim Raja Ali Haji yang telah memberikan dukungan berupa dana penelitian, sehingga penelitian ini dapat diselesaikan dan terpublikasi.

\section{KESIMPULAN}

Berdasarkan penelitian yang telah di lakukan menggunakan metode K-Means untuk penentuan nilai centroid dapat dilihat bahwa metode k-means memberikan pengaruh terhadap hasil pengenalan yang dilakukan oleh sistem sehingga hasil yang didapatkan lebih baik. Jumlah terbaik yang diperoleh dari perngujian centroid adalah 7 dengan MAD sebesar 0,98.

Pada penelitian ini penggunaan metode RBF menghasilkan tingkat akurasi pengenalan yang rendah. Dari 12 percobaan terdapat 6 percobaan benar dan 6 percobaan salah sehingga memiliki akurasi sebesar 50\%. Rendahnya tingkat akurasi dari pengenalan disebabkan oleh pencahayaan citra yang tidak tetap. Hal ini mempengaruhi data ciri yang di jadikan data latih menjadi tidak beraturan. Rentang data antara citra ikan segar dan ikan tidak segar tidak begitu besar sehingga nilai hasil yang di dapat dari pengenalan RBF hanyalah nilai rata rata.

\section{SARAN}

Berdasarkan hasil kesimpulan dari penelitian ini, saran yang dapat dilakukan untuk membuat hasil pengenalan yang lebih baik pada penelitian selanjutnya sebaiknya lebih memperhatikan proses pengambilan gambar yang akan menjadi data latih bagi metode pengenalan. Pengambilan gambar harus dengan kondisi pencahayaan yang tetap.

\section{REFERENSI}

[1] Thirumavalavan, S., \& Jayaraman, S., "Classification of Skin Cancers using Radial Basis Function Network", 151(4), 19-22, 2016.

[2] Rakhmawati, R. P.,"Sistem Deteksi Jenis Bunga Menggunakan Nilai HSV dari Citra Mahkota Bunga". Universitas Stikubank, Semarang, 2013. 
[3] Airlangga, P. U., Variasi, S., Perendaman, W., \& Simulated, D., 2007, BAB II TINJAUAN PUSTAKA 2.1 Tulang, (Jawetz 1986), 7-25.

[4] Maura, A.W., "Identifikasi Kematangan Buah Apel Dengan Gray Level CoOccurrence Matrix (GLCM), Teknik Informatika Komputer, (114), 2017.

[5] Clauditta, Lovidianti, Alamsyah, D., \& Yohannes., "Menghitung Jumlah Orang dengan Ekstraksi Fitur Gray Level Cooccurrence Matrix (GLCM)". STMIK GI MDP Palembang, (x), 2016.

[6] Nasari, F., \& Darma, S. "Penerapan KMeans Clustering pada Data Penerimaan Mahasiswa Baru". Seminar Nasional Teknologi Informasi Dan Multimedia 2015, 6-8, 2015. 